Article

\title{
Strange Bedfellows: Ecosystem Services, Conservation Science, and Central Government in the United Kingdom
}

\author{
Ricky N. Lawton * and Murray A. Rudd * \\ Environment Department, University of York, Heslington, York YO10 5DD, UK \\ * Authors to whom correspondence should be addressed; E-Mails: ricky.lawton@york.ac.uk (R.N.L.); \\ murray.rudd@york.ac.uk (M.A.R.); Tel.: +44-1904-324063; Fax: +44-1904-322998.
}

Received: 16 April 2013; in revised form: 22 May 2013 / Accepted: 7 June 2013 /

Published: 19 June 2013

\begin{abstract}
The Natural Environment White Paper represents the most important shift in conservation policy in the United Kingdom for over 20 years. It formalizes the ecosystem services approach within policy objectives and emphasizes the economic value of ecosystem services. The ecosystem services approach embodies different meanings to different groups, each suggesting distinct governance paradigms and management tools. While conservationists' support for the ecosystem services approach may stem from arguments for integrated and holistic management of natural systems, valuation efforts seek to apply economic tools to complex ecosystem processes as a means of increasing the policy salience of ecosystem services for management. Does this coupling make for strange bedfellows? We apply the Advocacy Coalition Framework to examine the alignment of the values and beliefs of key United Kingdom actors. Understanding core and peripheral values may help actors anticipate where cooperation and conflict arise, and the potential longevity of policy partnerships.
\end{abstract}

Keywords: ecosystem approach; ecosystem services; policy change; advocacy coalitions; conservation policy

\section{Introduction}

There is widespread consensus among scientists that ecosystems are under tremendous pressure from human activities [1]. The loss of biological diversity is increasing at a rate beyond planetary 
boundaries [2] and is an issue in all regions and types of ecosystems [3]. An integrated approach to ecosystem-based management (EBM) increasingly became the focus of conservation scientists and environmental managers in the 1980s and 1990s [4,5]. Since the 1990s, a broader ecosystem services (ES) approach to management that also considers economic values [6] has gained traction in national (e.g., UK National Ecosystem Assessment) and international policy initiatives [7,8].

Informal interviews with conservation practitioners and agency officials in the United Kingdom (UK) suggested that their current perception of the ES approach to environmental management incorporates two distinct aspects. The first consists of a scientific systems paradigm for understanding and managing the natural world. It entails system-orientated mental constructs for environmental managers and decision-makers [9] and draws on EBM perspectives.

The second aspect is the conceptualization of natural capital stocks providing flows of economically valuable ES to humans [6]. Ecosystem services provide a powerful analogy for the communication of environmental degradation in the dominant economic language of decision-making [10]. While the roots of the ES concept trace back at least to the 1970s [11], ES thinking has only come into the mainstream relatively recently $[11,12]$.

The distinct emphases of the two approaches to environmental management may appeal more or less to individuals and interest groups who hold different values. While the holistic aspect of EBM may be broadly embraced by conservationists, the quantification of ES has been criticized for "crowding out" traditional conservation interventions [13] or ignoring nature's intrinsic values not amenable to valuation [14].

In the UK, the ES approach has been adopted enthusiastically by the central government. The Natural Environment White Paper (2011) (the "White Paper") [15] was the first national-scale environmental legislation in the UK for over 20 years. It presented clear high-level policy direction that accounts for ES in local and national decision-making. It had a strong focus on the economic benefits of ES, national natural capital accounting, and the effects of ES on human health and well-being.

Why have UK policy-makers so readily adopted the ES approach and is this support sustainable over the long-term? Policy-makers in the UK seem, in fact, to have adopted the ES approach faster than the scientific community could provide the ecological and economic support for new policies. For example, ecologists face challenges in quantifying links between ecological structure, function, and ES of interest to policy-makers [16]. Economists are often unable to provide evidence regarding the range of ecosystem service values needed by policy-makers. The UK National Ecosystem Assessment (2011) [17], for instance, described non-monetary benefits of ecosystems to people in terms of health and shared social values rather than economic values. Current benefit transfer approaches used in lieu of primary valuation research also exhibit notoriously high transfer errors [18].

Is the dual focus on ecological systems and valuation of ES sufficient to ensure effective environmental protection? Will different actors in the policy process engage and coordinate given potentially divergent core beliefs that emphasize different aspects of the ES approach? If beliefs diverge, will weaker agreement on short-term policy and implementation issues remain? We suggest that sustainable long-term collaboration needed to successfully implement the ES approach requires an alignment of underlying motivations among policy actors. If, instead, the groups are ill-matched, they will make "strange bedfellows" [19]. We draw on the UK case to illustrate how policy actors' beliefs 
can be assessed and how this may help us anticipate whether the ES approach might, to stretch the strange bedfellows analogy, involve a short-term "policy fling", medium-term "issue cohabitation", or long-term "policy partnership".

\section{Policy Coalitions}

The Advocacy Coalition Framework (ACF) was developed to analyze policy implementation and change by studying how policy actors can be aggregated into advocacy coalitions bound by shared motivations and beliefs [20]. The ACF specifies three levels at which actors' beliefs are assessed: deep core; policy core; and secondary. Deep core beliefs are strongly held, relating to issues such as core political perspectives, inter-generational equity, and the existence of intrinsic environmental values [21]. Policy core beliefs are specific to particular policy issues, relating to basic normative commitments and problem causality [20]. Secondary beliefs are narrower still in scope, typically focusing on how core beliefs should be implemented in practical policies. The ACF predicts that groups who agree at the deep core level will also agree more at all lower hierarchical levels [20]. However, recent findings suggest that coalitions that differ in deep core beliefs may still converge with regards to policy core and secondary beliefs [21]. For instance, transient coalitions may unite around a shared set of short- to medium-term material interests [22].

We extend the strange bedfellows metaphor to examine varying degrees of convergence at the three levels of beliefs. In the long-term, sustainable policy partnerships overlap or converge on deep core, policy core, and implementation-oriented secondary beliefs (Figure 1). High levels of alignment increase policy partnership longevity, likely providing the predictability required for long-term, high-cost institutional innovation [23]. While it definitely pushes the analogy too far to say that sustainable policy partnerships are based on unconditional love, there are shared core values that help partners align interests over the long-term. When limited convergence exists at the deep core level, issue cohabitation may still exist at the policy core level. When coalition interests converge only slightly at the policy core level there still can be situations where short-term motivations exist for transient cross-coalition liaisons - policy flings - in which partners unite around a shared set of short-term material interests.

Understanding the strength of motivating beliefs as the basis of collaboration between coalitions can, we believe, be used to anticipate the sustainability of the ES approach. For example, institutional innovations to protect ecological networks at the landscape and national scale are likely to require long-term, and expensive, commitment by policy partners in order to effectively address diverse stakeholder concerns, legal issues, negotiations, public communications, and policy implementation. In the UK, pilot Local Nature Partnerships and Nature Improvement Areas are based on the assumption that durable partnerships between local government, environmental non-government organizations (ENGOs), and local stakeholders and landowners will emerge and can be informed by conservation scientists and mediated by central government agencies. These partnerships are unprecedented in the faith they put in local energy, commitments, and ownership.

As in any relationship, power issues may also come into play. Collaboration at the policy development phase may give way to the domination of one coalition at the implementation stage. It is 
our belief that in the ES approach this may be translated into policies that focus more on the valuation of ES, in line with central government core beliefs, than on the systems-oriented EBM orientation.

Figure 1. Three classes of "strange bedfellow" coalitions that vary in their overlap in values and interests.

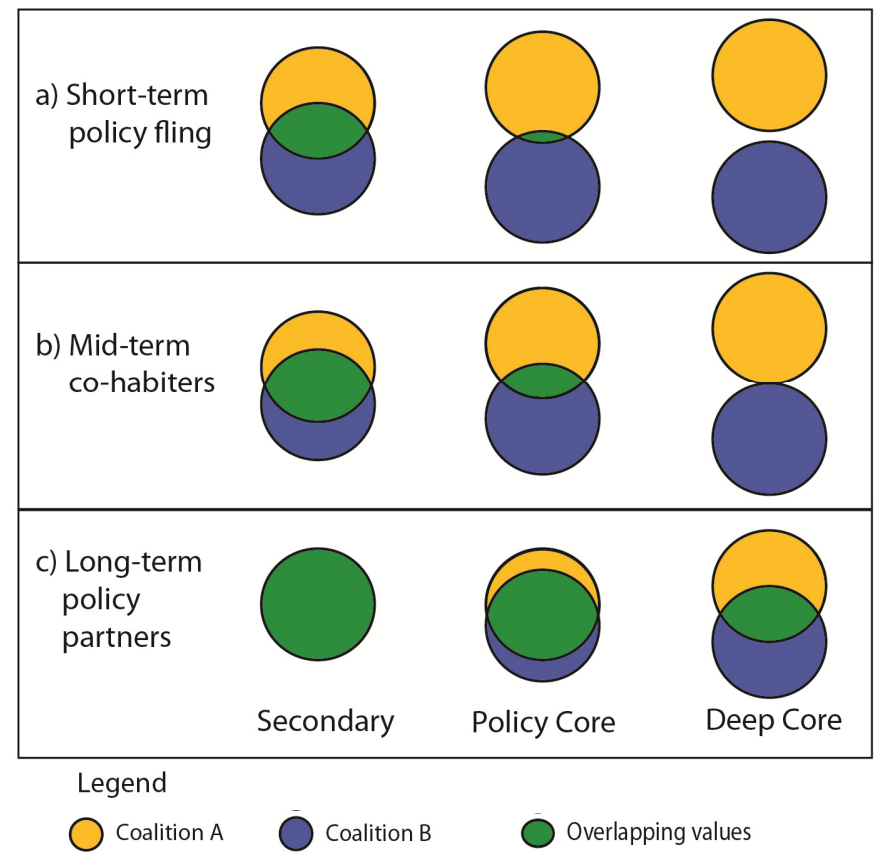

\section{Methods}

\subsection{Documentation Coding}

The White Paper was preceded by extensive public consultation inviting written responses from interested parties. To assess the types of advocacy coalitions active during White Paper development, we conducted a content analysis and coded 36 consultation responses with NVivo 10 [24]. This represented the total sample of consultation responses obtained from exhaustive online searches. Five groups who submitted comments were considered: central government; conservation scientists; landowner groups; environmental agencies, including the Department for the Environment and its "arms-length" implementation bodies, the Environment Agency, and Natural England; and ENGOs (list of consultation respondents: Table 1). We confirmed coalition labeling with analysis of each organization's stated aims, as outlined in the consultation response, or on the organization's web site. This provided a set of five coalitions for ACF analysis.

Consultation documents were coded with labels reflecting themes or concepts of interest (using Nvivo 10). Our analysis involved the development and application of codes both prior to, and deriving from, the data [25]. Our initial broad coding was based on theoretical insights regarding conservation science and "central" liberal politico-economic views derived from background literature. Conservation science views were derived from literature on the human-nature dichotomy nature [26,27], wildlife conservation [28-31], the intrinsic value of nature [14,32,33], and limits to growth and sustainability discourse [34-36]. "Central" views were derived from liberal contracturalist theory [37-39], New Public Management (NPM) [40], and deliberative governance literature [41,42]. Belief components 
were developed from a set of six deep and policy core beliefs precepts as outlined by Sabatier [43]. These included beliefs around: the nature of man; orientation on basic value priorities; identification of groups whose welfare is of greatest concern; the overall seriousness of the problem; basic causes of the problem and; the proper distribution of authority. Our second phase of coding derived from consultation responses. Codes were free to be adjusted iteratively during the main coding process. For example, consultation presentations on issues such as "ecosystem services", "human health and wellbeing", "measurement of natural capital", etc., were collected under the coding "natural value and valuation" (Table 2). In this way, the broad scope of issues and concerns addressed in the source data was given shape (Table 2) in a way that allowed ACF analysis.

Table 1. Consultation responses.

\begin{tabular}{|c|c|}
\hline Coalition & Organization \\
\hline Conservation science & $\begin{array}{l}\text { Institute of Ecology \& Environmental Management, Kew Gardens, the British Ecological } \\
\text { Society, Institute of Environmental Management \& Assessment, the Royal Town Planning } \\
\text { Institute, Society of Biology, Geological Society, the Soil Association, the } \\
\text { Buckinghamshire \& Milton Keynes Biodiversity Society and the National Parks Authority. }\end{array}$ \\
\hline ENGOs & $\begin{array}{l}\text { Campaign to Protect Rural England, Green Space SE, the Kent Wildlife Trust, the Wildlife } \\
\text { \& Countryside Link, SW Landscapes, WWF, Environment Protection UK, the Green Party, } \\
\text { Low Emissions Strategy Partnership Board, the Sustainable Development Commission, } \\
\text { Vine, the Devon Countryside Access Forum, the Anglers Association and the Shropshire } \\
\text { Hills AONB Partnership. }\end{array}$ \\
\hline $\begin{array}{l}\text { Environmental } \\
\text { agencies }\end{array}$ & $\begin{array}{l}\text { Consultation responses from DEFRA and Natural England. Department for Environment, } \\
\text { Food and Rural Affairs Natural Environment White Paper: Stakeholder Workshops. } 1 \text { and } 4 \\
\text { November } 2010 \text {-Notes setting out topics to be covered. }\end{array}$ \\
\hline Central government & $\begin{array}{l}\text { "An Invitation to Shape Nature": consultation invitation; summary of responses; DEFRA } \\
\text { web resources. }\end{array}$ \\
\hline Landowners & $\begin{array}{l}\text { National Farmers Union, the Yorkshire \& Humber Rural Affairs Forum, the Manhood } \\
\text { Peninsula Steering Group and the Country Land and Business Association. }\end{array}$ \\
\hline Other & Research councils UK; Play England consultation; Heritage Alliance \\
\hline
\end{tabular}

Table 2. Hierarchical belief coding.

\begin{tabular}{llllll}
\hline Deep Core & ENGO & Cons. Sci. & Agency & Central Govt. & Land-owner \\
\hline Alternatives to Neoliberal Model & 61 & 37 & & & 71 \\
Deliberative Democracy & & & 21 & 23 & 95 \\
Economic Growth Imperative & & & 6 & \\
Environment \& Society Balance & 45 & 71 & 18 & & \\
Environmental Fragility \& Limits & 59 & 62 & & \\
Faith in Technocratic Solutions & 58 & 18 & & \\
High Value Given to Nature & 41 & 21 & & \\
Human Pressures on the Environment & 41 & & & \\
NGO Mission & 83 & & 3 & \\
New Public Management & 56 & 24 & & \\
Resource Use \& Depletion & & & & \\
Statistics, Indicators \& Targets & 44 & 23 & & \\
Understanding Ecological Processes as & & & & \\
Requisite to their Preservation & & &
\end{tabular}


Table 2. Cont.

\begin{tabular}{llllll}
\hline Policy Core & ENGO & Cons. Sci. & Agency & Central Govt. & Land-owner \\
\hline $\begin{array}{l}\text { Doubts over Market Valuation } \\
\text { Doubts \& Refutation of Science }\end{array}$ & 20 & 12 & 5 & & 25 \\
$\begin{array}{l}\text { Ecosystem Approach } \\
\text { Engaging Civil Society }\end{array}$ & 213 & 116 & 39 & 59 & \\
Environmental Pressures & & 81 & 7 & 18 & 9 \\
Incentives not Regulation & & & & & 22 \\
Natural Value \& Valuation & 64 & 61 & 29 & 26 & 62 \\
Pressures on Growth & & & & 56 & \\
\hline Secondary & & & & & \\
\hline Command \& Control & 9 & & & 14 & \\
Economic \& Market Instruments & & 41 & & 3 & \\
Evidentiary Foundations & 15 & 25 & 8 & 24 & 22 \\
Metrics \& Measurement & & 7 & & & \\
Need for Political Leadership & 146 & 85 & 18 & 69 & \\
Regulatory Instruments & 90 & 35 & 12 & & \\
\hline
\end{tabular}

\subsection{Quantitative Coding Analysis}

A coding observation was ascribed for each instance that an issue was mentioned within a paragraph. Quantitative data was subsequently divided by coalition membership to provide total numbers of coding observations for each issue per coalition.

Codes were divided into deep, policy and secondary belief levels for each coalition based on ideological closeness with pre-coding deep core issues (deep core), centrality to the substantive policy issue (policy core), and implementation practicalities (secondary) [20]. We took shared coding as an indication of belief alignment. We posited that higher numbers of shared belief issues for each coalition represented stronger coalition alignment (represented on y-axis of Figure 2). Magnitude of coding observations was visualized by circle diameter (Figure 2).

We represented overlapping coalition beliefs between conservation science and central government coalitions on a Venn diagram (area proportional to coding observation magnitude) at three levels of deep core, policy core, and secondary beliefs (Figure 3). Belief issues from our documentary coding table (Table 2) were labeled in the Venn diagram. Figure 4 factored shared beliefs between conservation science, central government, and the agency coalition into an area proportional Venn diagram to demonstrate overlap, and the bridging role played by the agency coalition.

\section{Results}

The number of coding observations shared by the groups submitting White Paper consultation comments is shown in Figure 2. The conservation science (744 comments over 132 issues) and ENGO (1076 comments over 150 issues) dyad displayed a high level of alignment of issue codes at the deep core level, while the conservation science and environment agency (199 comments over 66 issues) pairing exhibited four shared issue codes. For most dyads, however, correspondence between issue codes was low at the deep core level. Issues raised during White Paper consultations by various groups 
showed increased alignment at the policy core level and almost total alignment at the secondary belief level.

Figure 2. Shared beliefs between coalition pairs (size of each circle represents the number of shared beliefs for paired coalitions at each Advocacy Coalition Framework (ACF) belief level).

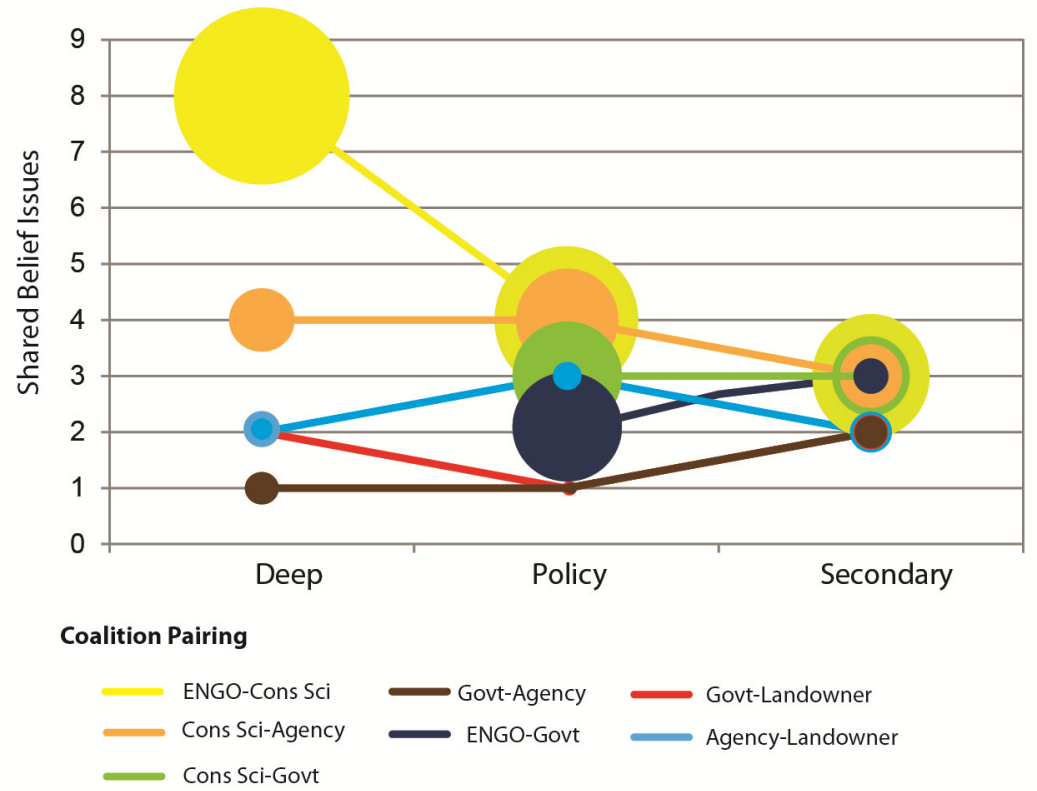

At the deep core level, there was complete divergence of beliefs between the conservation and central government (330 comments over 94 issues) groups (Figure 3). Deep core belief coding observations for the conservation science group related to broadly pro-environment issues like the fragility of nature, the high value of the environment to humans, and the environment-society balance, including concern for human pressures on the environment and the need for behavioral change. Concern over the dominant neoliberal worldview was also evident.

Figure 3. Venn diagram of belief agreement between conservation science and central government coalitions (area proportional to number of coding observations).

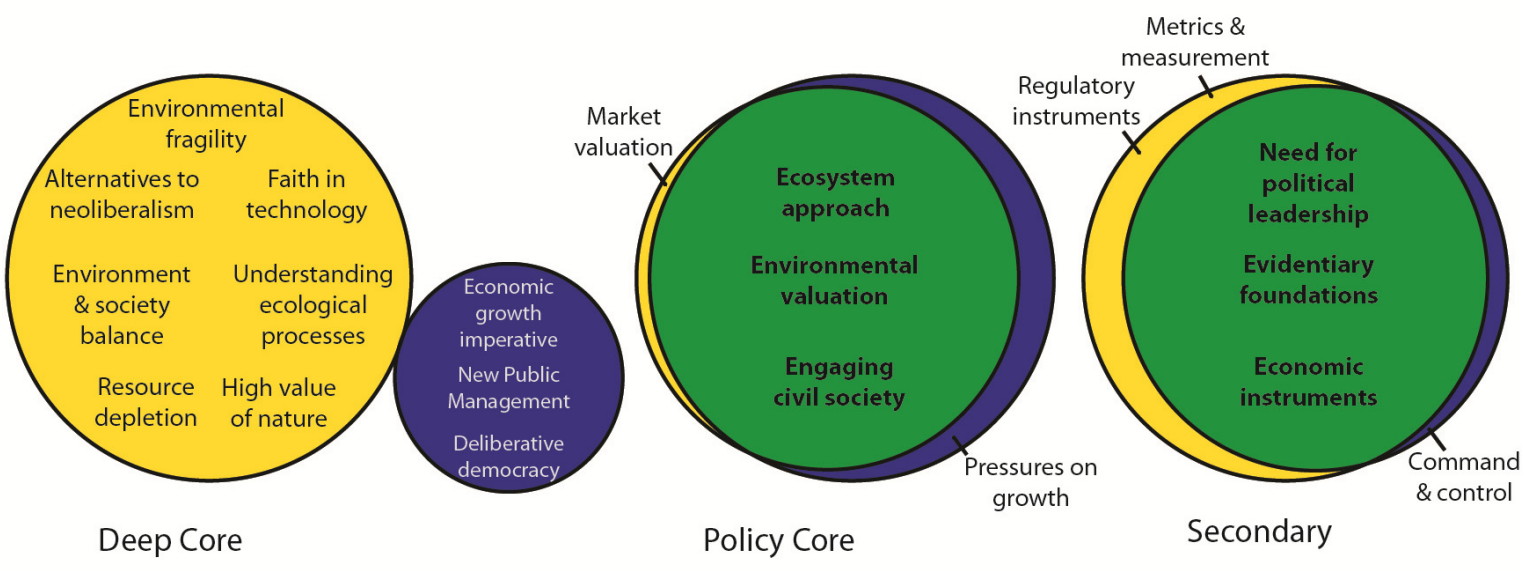

Legend

Conservation Science - Central Government - Overlap $\square$ 
The central government group commented on deep core issues centered on governance systems and societal goals. The importance of deliberative democracy and the New Public Management paradigm, which emphasizes efficient market-led delivery of public services, were important political issues. Neoclassical or neoliberal conceptions of society and the imperative for growth were important economic issues. Policy core beliefs converged more between groups, particularly on issue-specific topics like the ES approach and civil society engagement. Still, divergence existed over issues of market approaches to environmental management. Agreement at the level of secondary belief issues was much broader.

The relationship between other groups was also informative. The conservation science and ENGO pairing showed greatest agreement at the deep core levels. Landowners (289 comments over 114 issues) were isolated in many of their beliefs, tending to align with the central government or agencies when they did show agreement. The agency group acted as an important bridge between the conservation and central government coalitions (Figure 4). Those coalitions were only connected indirectly at the deep core level by the beliefs they shared with the agency coalition. At the policy core and secondary levels, beliefs were shared more equally between the three coalitions.

Figure 4. Venn diagram of agency coalition bridging function (area proportional to number of coding observations).
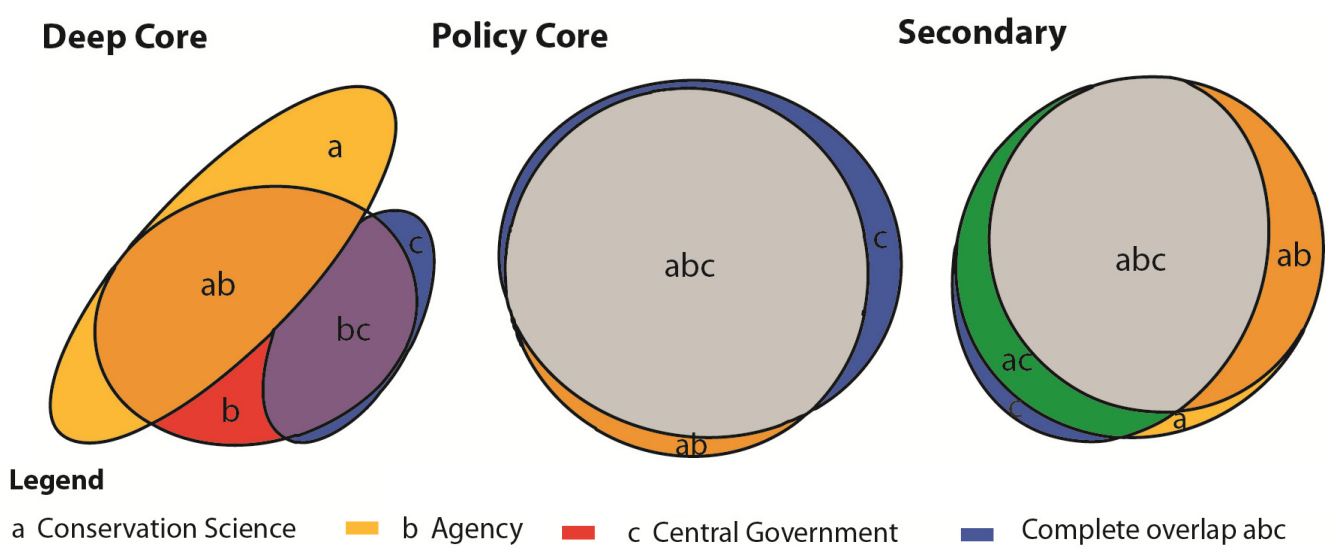

\section{Discussion}

There appeared to be convergence among various conservation policy actors at the policy core and secondary belief levels, including broad agreement that the ES approach was a positive progression in environmental management. The UK conservation science and central government policy coalition seems to have moved beyond a short-term policy fling; they seem to have moved in together, becoming medium-term issue cohabiters.

Convergence of beliefs at the policy core level does not itself guarantee the sustainability of long-term policy partnerships, as it may mask more fundamental disagreements in deep core beliefs. Sustainable policy partnerships can, however, be held together so long as both coalitions satisfy enough of their deep core motivations through the policy action. For conservation science and ENGOs, the White Paper advanced the protection of the natural world and was a progressive step in environmental management. For the central government, the White Paper achieved medium-term policy action objectives in the environmental sphere. The valuation of anthropocentric ecosystem 
service benefits also aligned well with central government deep core economic growth imperatives. The White Paper's focus on local knowledge and non-traditional governance regimes can also be made to fit with New Public Management preferences for regulatory reductions and economically efficient forms of governance [40]. Finally, at the center of the ecosystem service approach is an economic metaphor between the stock of natural capital and the flow of valuable services to humanity, an understandable idea that is politically saleable.

One could argue that there is an element of "co-opting" of economic arguments by the conservation community as it seeks to gain political traction for the overall ecosystem approach. The aim, presumably, is to appeal to policy-maker deep core values such as a faith in free market solutions. In this way, the UK conservation science community seeks to assure policy partnership sustainability by adopting positions close to government's policy core despite holding divergent deep core beliefs. Can one side appease or both sides compromise to align values further, cementing a long-term policy relationship? That remains to be seen and will depend on a variety of pressures and drivers.

\section{Positioning the Ecosystem Services Approach}

\subsection{A simple Ecosystem Services Framework}

Conceptualizing the ES approach in a matrix that accounts for the scale of ecological and economic integration (Figure 5) may be useful for thinking about drivers of change. On the ecological systems axis, one can focus on context-dependent species and habitats or, at a broader level, on ecosystems and landscapes. On the valuation axis, the focus can range from narrow financial analyses to total economic value (TEV) [44] of an entire suite of ES. The two approaches are synthesized in the upper right-hand quadrant, the ES realm. In the upper left quadrant is the EBM realm. In lower left quadrant, species- and habitat-oriented assessments are more typical of environmental impact (EI) assessments. In this technical-rational EI realm there often are only modest levels of ecological and economic integration [45]. In the lower right quadrant, broad economic analyses are conducted for specific contexts. This TEV realm is where environmental economics research is typically focused. This was exemplified by the US response to the 1989 Exxon-Valdez oil spill [46], where arguments over compensation for personal damages stemming from ecological damage and restoration led to extensive litigation, new research, and controversy. 
Figure 5. Paired grids showing gradations of the ecosystem approach under (a) academic $\&$ political pressures; and (b) prospective national trajectories.

(a) Pressures

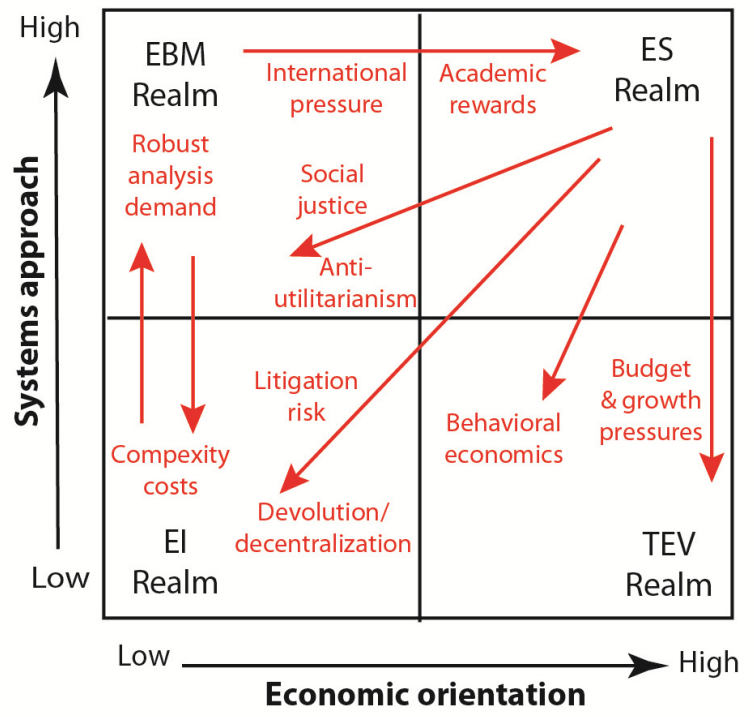

(b) National trajectories

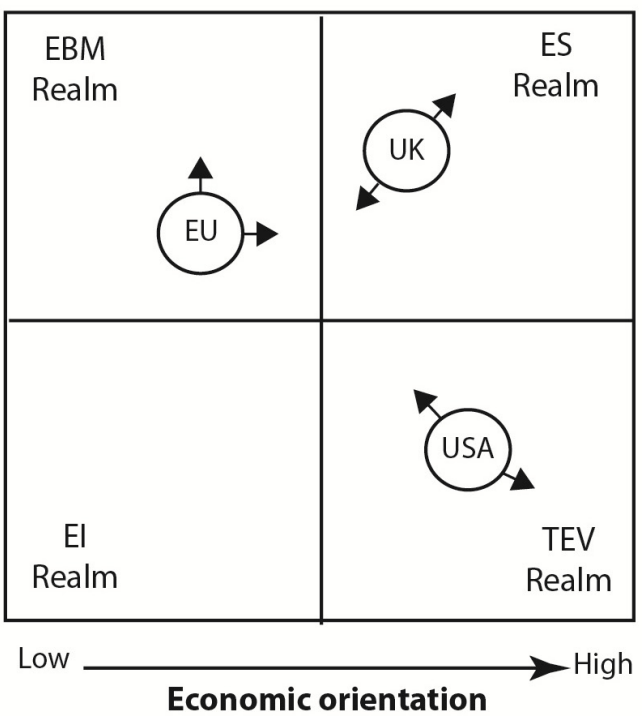

\subsection{Drivers of Environmental Management Approach}

A variety of factors may affect where in this framework a specific regime, policy, project, or event best fit. It is useful to consider pressures that may change support for various environmental management approaches (Figure 5a). For example, in the EI realm scientific needs for more robust ecosystem-oriented analyses are potential drivers for a move to the EBM realm. However, the complexity of ecological analyses, which can be expensive and inconclusive with regards to links between ecological structure and function, may act as a counter-force.

There is now substantial international policy pressure to move from the EBM to ES realm to create economic policy relevance for growth-oriented governments. For example, the EU Natura 2000 network of protected sites, a key EBM-oriented initiative of the Habitats Directive [47], did not emphasize economic valuation but recent EU initiatives [8] are creating pressure to incorporate valuation in environmental policy [48]. Broad syntheses typical of the ES realm also tend to be highly cited (e.g., six of the 10 most influential studies in the field of environmental and ecological economics from 2000 to 2009 directly relate to ecosystem services [49]). Academic rewards may therefore be a driver towards the ES realm (although this is not a pressure exclusive to ES research).

Counter pressures may also be important. Issues of social and environmental justice [50] and push back against overly utilitarian approaches to environmental management [14] provide potential countervailing pressures from the ES to EBM realm. Behavioral economics [51] is also becoming increasingly influential within the economics discipline and behavioralists often question the validity and utility of ES valuation results.

Budgetary pressures may constrain integrated studies when long-term or highly transdisciplinary research is needed, effectively putting pressure towards the EI realm. The drive towards decentralization and devolution of governance can also lead to pressure to simplify ecological analyses at a local or regional level. In the UK, the effect of devolution of governance to local levels may be mitigated by 
Local Nature Partnerships and Nature Improvement Areas, which promote ecosystem-targeted practices like wildlife corridors, stepping-stones, and 'landscape-scale' landowner-ENGO partnership management [15]. The success of those programs, however, remains to be seen; our analysis suggested that shared policy core values diverged substantially between landowner and ENGO groups.

Another important driver of changes in environmental management orientation is litigation. While the US Endangered Species Act (ESA) legislation precludes economic concerns from explicitly influencing listing decisions, the risk of private sector litigation arising from ESA restrictions on property owners means that economic concerns may exert pressure toward the EI realm. The government may be concerned with litigation risks arising from direct financial impacts, business, or jobs, as well as opportunity costs to the private sector. Conversely, it is also possible that ENGO litigation puts the opposite pressure on governments, creating pressure to manage at higher levels of ecosystem integration [51].

\section{Conclusions}

Should national policies aspire to the ES approach, giving weight to ecosystem-oriented ecological analyses in combination with high levels of economic integration? Given the variety of ecological, economic, social, and governance factors influencing environmental management, there is no simple answer as to whether the ES approach should be more or less preferred than other management approaches. Co-habitation between regulators and conservation scientists along the UK line may be desirable but this requires understanding policy values at different levels and the possible effect of short- and long-term drivers of those values. We should expect that the slow evolution of core values in society and the quicker evolution of policy core values for various policy actors will influence the stability of existing and newly developing policy partnerships.

While ES-oriented management may be "logical' in some countries and political contexts, it is also possible to foresee a future, especially as societies continue to push beyond planetary boundaries on multiple fronts [52], in which our collective obsession with consumption-driven economic growth demands a move away from the ES realm. This may involve, for instance, cost-effective EBM-oriented measures that at minimum cost help us achieve shared societal goals based on equity, sustainability, and well-being. We find the strange bedfellows metaphor a useful heuristic for envisioning the potential for convergence or divergence of deep core and policy core beliefs, and anticipating the possible consequences of various types of conservation policy liaisons.

\section{Acknowledgements}

In memory of Paul Sabatier, without whose insights this paper would not have been written and the world of academia would be much poorer. We gratefully acknowledge UK Economic and Social Research Council doctoral funding to RNL. 


\section{References}

1. Cardinale, B.J.; Duffy, J.E.; Gonzalez, A.; Hooper, D.U.; Perrings, C.; Venail, P.; Narwani, A.; Mace, G.M.; Tilman, D.; Wardle, D.A. Biodiversity loss and its impact on humanity. Nature 2012, 486, 59-67.

2. Rockström, J.; Steffen, W.; Noone, K.; Persson, Å.; Chapin, F.S.; Lambin, E.F.; Lenton, T.M.; Scheffer, M.; Folke, C.; Schellnhuber, H.J.; et al. A safe operating space for humanity. Nature 2009, 461, 472-475.

3. Rudd, M.A. Scientists' opinions on the global status and management of biological diversity. Cons. Biol. 2011, 25, 1165-1175.

4. Christensen, N.L.; Bartuska, A.M.; Brown, J.H.; Carpenter, S.; D’Antonio, C.; Francis, R.; Franklin, J.F.; MacMahon, J.A.; Noss, R.F.; Parsons, D.J. The report of the Ecological Society of America committee on the scientific basis for ecosystem management. Ecol. Appl. 1996, 6, 665-691.

5. Grumbine, R.E. What is ecosystem management? Cons. Biol. 1994, 8, 27-38.

6. Daily, G.C. Nature's Services: Societal Dependence on Natural Ecosystems; Island Press: Washington, DC, USA, 1997.

7. Hassan, R.; Scholes, R.; Ash, N.; Carpenter, S.R.; Pingali, P.L.; Bennett, E.M.; Zurek, M.B.; Chopra, K.; Leemans, R.; Kumar, P.; Simons, H. Ecosystems and Human Well-Being Volumes: Current State and Trends: Findings of the Condition and Trends Working Group of the Millennium Ecosystem Assessment; Island Press: Washington, DC, USA, 2005.

8. TEEB - The Economics of Ecosystems and Biodiversity. The Economics of Ecosystems and Biodiversity: Mainstreaming the Economics of Nature: A Synthesis of the Approach, Conclusions and Recommendations of TEEB; Earthscan, Routledge: London, UK, 2010.

9. Yaffee, S.L. Three faces of ecosystem management. Cons. Biol. 1999, 13, 713-725.

10. Noss, R.F.; Cooperrider, A. Saving Nature's Legacy: Protecting and Restoring Biodiversity; Island Press: Washington, DC, USA, 1994.

11. Gómez-Baggethun, E.; de Groot, R.; Lomas, P.L.; Montes, C. The history of ecosystem services in economic theory and practice: From early notions to markets and payment schemes. Ecol. Econ. 2010, 69, 1209-1218.

12. Bateman, I.; Mace, G.; Fezzi, C.; Atkinson, G.; Turner, K. Economic analysis for ecosystem service assessments. Environ. Resour. Econ. 2011, 48, 177-218.

13. Redford, K.H.; Adams, W.M. Payment for ecosystem services and the challenge of saving nature. Cons. Biol. 2009, 23, 785-787.

14. Spash, C.L. Ethics and environmental attitudes with implications for economic valuation. J. Environ. Manag. 1997, 50, 403-416.

15. Department for Environment, Food and Rural Affairs (DEFRA). The Natural Choice: Securing the Value of Nature; DEFRA: London, UK, 2011.

16. Balvanera, P.; Pfisterer, A.B.; Buchmann, N.; He, J.-S.; Nakashizuka, T.; Raffaelli, D.; Schmid, B. Quantifying the evidence for biodiversity effects on ecosystem functioning and services. Ecol. Lett. 2006, 9, 1146-1156. 
17. UK National Ecosystem Assessment. The UK National Ecosystem Assessment Technical Report; United Nations Environment Programme, World Conservation Monitoring Center (UNEP-WCMC): Cambridge, UK, 2011.

18. Environmental Value Transfers: Issues and Methods; Navrud, S., Ready, R., Eds.; Kluwer Academic Publishers: Dordrecht, The Netherlands, 2007.

19. Mahoney, C. Networking vs. allying: the decision of interest groups to join coalitions in the US and the EU. J. Eur. Public Policy 2007, 14, 366-383.

20. Policy Change and Learning: Advocacy Coalition Approach; Sabatier, P.A., Jenkins-Smith, H.C., Eds.; Westview Press Inc.: Boulder, CO, USA, 1993.

21. Weible, C.M.; Sabatier, P.A. Coalitions, science, and belief change: Comparing adversarial and collaborative policy subsystems. Policy Stud. J. 2009, 37, 195-212.

22. Szarka, J. Bringing interests back in: Using coalition theories to explain European wind power policies. J. Eur. Public Policy 2010, 17, 836-853.

23. North, D.C. Institutions, Institutional Change and Economic Performance; Cambridge University Press: Cambridge, UK, 1990.

24. NVivo Qualitative Data Analysis Software; QSR International Pty Ltd. Version 10, 2012.

25. Gibbs, G.R. Qualitative Data Analysis: Explorations with NVivo; Open University Publications: Maidenhead, UK, 2002.

26. Manning, A.; Serpell, J. Animals and Human Society: Changing Perspectives; Routledge: London, UK, 1994.

27. Coates, P. Nature: Western Attitudes Since Ancient Times; University of California Press: California, CA, USA, 2004.

28. Malcolm, L.H., Jr; Gibbs, J.P. Fundamentals of Conservation Biology, 3rd ed.; John Wiley \& Sons: Hoboken, NJ, USA, 2006.

29. Dyke, F.V. Conservation Biology: Foundations, Concepts, Applications; Springer: London, UK, 2008.

30. Barnosky, A.D.; Matzke, N.; Tomiya, S.; Wogan, G.O.; Swartz, B.; Quental, T.B.; Marshall, C.; McGuire, J.L.; Lindsey, E.L.; Maguire, K.C.; et al. Has the Earth's sixth mass extinction already arrived? Nature 2011, 471, 51-57.

31. Carson, R. Silent Spring; Houghton Mifflin Harcourt: Boston, MA, USA, 1962.

32. Callicott, J.B. Intrinsic value, quantum theory, and environmental ethics. Environ. Ethics 1985, 7, 257-275.

33. Worster, D. The intrinsic value of nature. Env. Rev. 1980, 4, 43-49.

34. Meadows, D.H.; Randers, J.; Meadows, D.L.; Behrens, W.W. The Limits to Growth: A Report for the Club of Rome's Project on the Predicament of Mankind, 2nd ed.; New American Library: New York, NY, USA, 1974.

35. Daly, H. Steady-State Economics, 2nd ed.; Island Press: Washington, DC, USA, 1977.

36. Our Common Future: From One Earth to One World; Report of the Brundtland Commission; World Commission on Environment and Development, United Nations, Oxford University Press: Oxford, UK, 1987.

37. Locke, J. Second Treatise of Government. In Two Treatises of Government [1689]; Hollis, T., Ed.; A. Millar [et al.]: London, UK, 1764; pp. 193-416. 
38. Rawls, J. A Theory of Justice: Revised edition; Harvard University Press: Harvard, BO, USA, 1999.

39. Scanlon, T.M. Contractualism and Utilitarianism. In Utilitarianism and Beyond; Sen, A., Williams, B., Eds.; Cambridge University Press: Cambridge, UK, 1982; pp. 103-129.

40. Pollitt, C.; Bouckaert, G. Public Management Reform: A Comparative Analysis-New Public Management, Governance, and the Neo-Weberian State; Oxford University Press: Oxford, UK, 2011.

41. Habermas, J. The Theory of Communicative Action: Reason and the Rationalization of Society; Beacon Press: Boston, MA, USA, 1985.

42. Dryzek, J.S. Foundations and Frontiers of Deliberative Governance; Oxford University Press: Oxford, UK, 2010.

43. Sabatier, P.A. The advocacy coalition framework: Revisions and relevance for Europe. J. Eur. Public Policy 1998, 5, 98-130.

44. Randall, A. Total economic value as a basis for policy. Trans. Am. Fish. Soc. 1987, 325-335.

45. Jay, S.; Jones, C.; Slinn, P.; Wood, C. Environmental impact assessment: Retrospect and prospect. Environ. Impact Asses. Rev. 287-300.

46. Carson, R.T.; Mitchell, R.C.; Hanemann, M.; Kopp, R.J.; Presser, S.; Ruud, P.A. Contingent valuation and lost passive use: Damages from the Exxon Valdez oil spill. Environ. Resour. Econ. 2003, 25, 257-286.

47. European Commission Managing Natura 2000 Sites. The Provisions of Article 6 of the "Habitats" Directive; European Communities: Luxembourg, 2000.

48. Dunbar, M.B.; Panagos, P.; Montanarella, L. European perspective of ecosystem services and related policies. Integr. Environ. Assess. Manag. 2013, 9, 231-236.

49. Hoepner, A.G.F.; Kant, B.; Yu, P.S. Environmental and ecological economics in the 21 st century: an age adjusted citation analysis of the influential articles, journals, authors and institutions. Ecol. Econ. 2012, 77, 193-206.

50. Guha, R.; Martinez-Allier, J. Varieties of Environmentalism: Essays North and South; Earthscan: London, UK, 1997.

51. Advances in Behavioral Economics; Camerer, C.F., Loewenstein, G., Rabin, M., Eds.; Russell Sage Foundation: Princeton, NJ, USA, 2004.

52. Taylor, E.; Pinkus, S. The effects of lead agency, non-governmental organizations, and recovery team membership on the identification of critical habitat for species at risk: Insights from the Canadian experience. Environ. Rev. 2013, 21, 93-102.

(C) 2013 by the authors; licensee MDPI, Basel, Switzerland. This article is an open access article distributed under the terms and conditions of the Creative Commons Attribution license (http://creativecommons.org/licenses/by/3.0/). 